\title{
BIBLIOTECA ESCOLAR: ESPAÇO DE ENSINO E DE APRENDIZAGEM
}

\author{
SCHOOL LIBRARY: TEACHING AND LEARNING SPACE \\ BIBLIOTECA ESCOLAR: ESPACIO DE ENSEÑANZA Y APRENDIZAJE
}

\author{
MANUELA CICONETTO BERNARDI ${ }^{1}$ \\ ORCID: https://orcid.org/0000-0002-0130-4845 \\ TERCIANE ÂNGELA LUCHESE ${ }^{2}$ \\ ORCID: https://orcid.org/0000-0002-6608-9728
}

PIMENTA, Jussara S. (Org.) Biblioteca Escolar: memória, práticas e desafios. Curitiba: CRV, 2018.

A obra "Biblioteca escolar: memória, práticas e desafios" lançada em 2018 tem como foco temático a biblioteca escolar. O livro visa auxiliar os profissionais vinculados à escola a pensarem no espaço "biblioteca" como um local de ensino e de aprendizagem para além da estrutura de guarda de livros e que esteja em diálogo constante com os sujeitos e com as práticas da instituição escolar. A obra é organizada por Jussara Santos Pimenta, Marcos Leandro Freitas Hübner, Hélder Henriques e Márcio Ferreira da Silva, realizada com apoio da FAPERO (Fundação Rondônia de Amparo ao Desenvolvimento das Ações Científicas e Tecnológicas e à Pesquisa do Estado de Rondônia) por meio do financiamento PAP-UNIVERSAL/FAPERO nº 003/2015.

A coletânea é composta por textos de diversos autores, antecedida pela apresentação realizada pelos organizadores e pelo prefácio de José María Hernández Díaz. Na sequência, sua estrutura segue em três partes, sendo a primeira intitulada Desenvolvimento da biblioteca escolar: aspectos bistóricos que compõe três textos. A segunda parte recebe o nome de Práticas de leitura e acesso à informação na biblioteca escolar: relato de experiências, sendo composta de quatro textos. Já a terceira Cultura local, representação da informação, letramento informacional e inclusão na biblioteca escolar é formada por diversas temáticas dentro do eixo bibliotecas escolares.

A apresentação dos organizadores intitulada Biblioteca escolar: presente! inicia com um compêndio acerca dos primórdios da biblioteca escolar, com ênfase no contexto brasileiro do século XX. O desenvolvimento, por vezes, traça um paralelo com a situação atual, trazendo um diagnóstico de continuidades e falta de iniciativas no desenvolvimento das bibliotecas escolares. Os organizadores refletem sobre a necessidade de políticas que ressignifiquem a biblioteca escolar e a insiram como espaço de aprendizagem. A obra é apresentada com a explicação das três partes que a compõem, bem como dos capítulos de cada autor e, além disso, é definindo como objetivo da coletânea o auxílio aos profissionais para que pensem na biblioteca como um espaço de aprendizagem.

No prefácio, José María Hernández Díaz, professor da Universidade de Salamanca, perscruta os elos que ligam a biblioteca com a escola. Para tal intento, leva em conta fatores históricos do ambiente escolar que eram divergentes com a ideação das bibliotecas e traz como importante difusor o modelo de Escola Nova. Sua escrita se apoia em compreender o objetivo de uma biblioteca escolar, que, para o autor, se baseia em um espaço educativo, motivador, que contribui na leitura e no conhecimento dos alunos. Destaca, ainda, o valor formativo e socializador da biblioteca escolar e o seu papel central na cultura escolar.

\footnotetext{
${ }^{1}$ Universidade de Caxias do Sul. Caxias do Sul, Rio Grande do Sul (RS), Brasil. <mcbernardi1@ucs.br>

${ }^{2}$ Universidade de Caxias do Sul. Caxias do Sul, Rio Grande do Sul (RS), Brasil. < taluches@ucs.br >
} 
Adentrando às três partes do livro, destaca-se a primeira, que reúne textos vinculados às investigações históricas sobre a biblioteca escolar.

Aline Santos Costa, em O projeto de bibliotecas da comissão nacional de literatura infantil: formação do leitor e a Escola Nova nos anos de 1930, explica a criação da Comissão Nacional de Literatura Infantil, projeto que preconiza a ideação de bibliotecas infantis para além de um local de guarda de livros, mas sim como um espaço de socialização, com a inclusão de atividades esportivas, educativas e recreativas, mostrando a preocupação já na década de 1930 com a questão da biblioteca e o seu papel educativo no ambiente escolar.

Hélder Henriques e Aline Martins de Almeida, em Um olhar sobre a biblioteca para o ensino dos cegos em castelo de vide (Portugal, séc. XIX-XX), tendo como objeto a biblioteca da Escola Profissional Branco Rodrigues, discutem a criação dessa biblioteca especializada para cegos, iniciando no séc. XIX em Portugal e terminando na década de 1940, incluindo as ideias que circundavam no meio social e no período. Assim, destacam a temática do ensino de cegos e instigam estudos que explorem a temática das bibliotecas especializadas.

Ao encerrar a primeira parte da coletânea $A$ história da Educação Básica no Brasil e as representações sociais sobre a biblioteca escolar: o passado que influencia no presente, Yaciara Mendes Duarte, por meio de levantamentos bibliográficos, analisa o estereótipo profissional com base no contexto histórico do ensino ligado à biblioteca escolar. Além disso, traz questões como a influência da mídia, reforçando representações que causam carências de políticas públicas e pouca utilização da biblioteca pelos indivíduos no processo escolar.

A segunda parte da coletânea é composta por relatos de experiências que entrelaçam as práticas de leitura e o acesso à informação nas bibliotecas escolares.

O texto $5^{a}$ Bienal do livro do Colégio Santo Agostinho - Unidade Belo Horizonte: "Legados da Grécia", de Belkiss Regina Del'Rio, Gilmara de Fátima Pereira da Silva e Maria Flávia Ribeiro Rodrigues, explica um evento que ocorre no Colégio supracitado e que está diretamente relacionado à biblioteca, mostrando que o ensino-aprendizagem é possível de forma coletiva quando são realizadas parcerias entre os agentes do processo educativo com o intuito promover o desenvolvimento dos educandos por meio de atividades interdisciplinares.

A produção Práticas pedagógicas na biblioteca escolar, de Flávia Brocchetto Ramos e João Paulo Borges da Silveira, realizada a partir de um estágio curricular, analisa as práticas junto a uma biblioteca escolar pública da localidade de Caxias do Sul - RS. As atividades e as observações coletadas mostram a difícil realidade encontrada em algumas bibliotecas como a carência de profissionais e de atividades que promovam ações entre a biblioteca e o ambiente escolar, outrossim, têm por objetivo evidenciar a urgência de reflexões sobre a necessidade de mudanças e de intervenções.

Leila Koch, em Biblioteca Eldo Ivo Klain no contexto escolar, tem a pretensão de mostrar a importância de uma biblioteca escolar ativa e em diálogo contínuo com os outros setores da instituição de ensino e seus agentes. Valendo-se da própria experiência na biblioteca explorada, apresenta as atividades e projetos desenvolvidos no que tange à leitura na formação do educando, mostrando por intermédio do relato de experiência um exemplo que pode ser seguido.

O último texto dessa parte, escrito por Marília de Abreu Martins de Paiva e Sindier Antonia Alves, Formandos agentes para biblioteca escolar: relato de um projeto de extensão universitária é o relato de um projeto de extensão, formado por voluntários, geralmente ligados à biblioteconomia, com o objetivo de capacitar outros profissionais que atuam em bibliotecas escolares. O projeto ocorreu por meio de visitas, de cursos e de formação. As autoras verificaram que os resultados foram satisfatórios e frisam a importância de tais ações para a difusão do conhecimento e de práticas ligadas à biblioteca escolar.

A terceira parte do livro é composta de textos com várias temáticas convergentes à coletânea, em especial, produções que atentam para as bibliotecas escolares sob matizes como competências informacionais, identidades, condições de instalação e de funcionamento, ensino-aprendizagem e políticas públicas e institucionais.

Djuli Machado de Lucca e Angerlânia Rezende, em Diretrizes para o desenvolvimento da competência em informação em bibliotecas escolares, trabalham na ligação entre a biblioteca escolar e o desenvolvimento de competências informacionais. Mediante uma busca bibliográfica e documental sintetizam as principais diretrizes para o desenvolvimento das competências informacionais. 
A produção Desafios contemporâneos à biblioteca escolar: as representações à edificação das identidades, de Márcio Ferreira da Silva, apresenta reflexões para a edificação das identidades afrodescendentes, colocando a biblioteca escolar como um espaço de difusão da cultura, finalizando com considerações acerca da representação do conhecimento por meio de sistemas de classificações utilizados em biblioteconomia como a Classificação Decimal Universal - CDU e a Classificação Decimal de Dewey CDD.

De Marcos Leandro Freitas Hübner, Jussara Santos Pimenta e Herta Maria de Açucena do Nascimento Soeiro, o texto A biblioteca nas escolas públicas estaduais de Porto Velho (RO): análise das condições de instalação e funcionamento advém de um projeto de pesquisa que teve como objetivo verificar as condições das bibliotecas escolares em Porto Velho (RO). Por meio de pesquisa bibliográfica e de visita, o resultado mostra que muitas ações são necessárias para o funcionamento básico das bibliotecas escolares dessa rede.

Em Integração da biblioteca escolar no processo de ensino-aprendizagem: da utilidade à necessidade, Vanessa Levatti Biff e Magali de Moraes Menti produzem reflexões sobre o papel da biblioteca no contexto escolar, tendo em vista identificar meios para o desenvolvimento do ensino-aprendizagem. As autoras colocam a biblioteca escolar como um recurso e sua manutenção deve estar alinhada ao projeto educacional.

E, em Acessibilidade em biblioteca escolar na perspectiva das politicas públicas e diretrizees institucionais do IFRO, Cleuza Diogo Antunes e Jussara Santos Pimenta buscam trabalhar na questão da acessibilidade de pessoas com deficiências nas bibliotecas do Ensino Regular e Técnico, tendo como base a verificação de questões de acessibilidade no Instituto Federal de Rondônia. As autoras identificam que, apesar da oferta de educação inclusiva, são necessárias diretrizes para a sua efetivação.

Ao findar as três partes do livro, são trazidas informações sobre cada um dos organizadores e também dos autores, situando o leitor nas temáticas e estudos em que cada um é especialista.

Como recorrência, ao longo dos capítulos, os autores colocam em destaque a Lei 12.244 de 2010, que dispõe sobre a universalização das bibliotecas nas instituições de ensino do País. Tal diretriz, de fato, mudou a perspectiva da biblioteca escolar, porém, próximo ao prazo máximo de seu cumprimento, que é 2020, é trazida a reflexão sobre a realidade estar diferente do proposto - que seria o cumprimento da Lei.

A leitura do livro é indispensável para quem se interessa por estudos sobre a temática bibliotecas escolares, sendo voltada, em especial, para a reflexão por parte dos agentes do processo educativo no que tange ao processo de ensino-aprendizagem e às diferentes perspectivas para pensar a temática: seja por meio das memórias, das práticas e dos desafios. No atual contexto escolar brasileiro, mediante severas dificuldades enfrentadas para concretizar o direito à aprendizagem, o tema das bibliotecas escolares, sob um calidoscópio de olhares investigativos, é trazido a lume nas páginas dessa obra. A produção cumpre o objetivo proposto pelos organizadores, porém, além disso, põe em questão a difícil realidade e a necessidade de constante diálogo para que ocorram mudanças e avanços, a fim de que as bibliotecas escolares possam se constituir em espaços privilegiados de construção de saberes e de difusão de conhecimento.

\section{REFERÊNCIA}

PIMENTA, Jussara S. (Org.) Biblioteca Escolar: memória, práticas e desafios. Curitiba: CRV, 2018.

Submetido: $26 / 11 / 2019$

Aprovado: $10 / 03 / 2020$ 